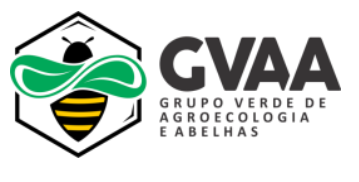

\title{
Uso dos resíduos orgânicos domésticos em vermicompostagem
}

\section{Use of household organic waste in the vermicomposting}

\author{
Janacinta Nogueira de Souza ${ }^{1}$; Brenda de Assis Ferreira Carvalho ${ }^{2}$; Adriana Marques Rocha ${ }^{3}$
}

${ }^{1}$ Graduada em Engenheira Ambiental e Sanitária e Mestranda acadêmica em Energias Renováveis do Instituto Federal de Educação, Ciência e Tecnologia do Ceará, Campus Maracanaú, Ceará, +5585996899927, janacinta.nogueira@gmail.com; ${ }^{2}$ Tecnóloga em Saneamento Ambiental e Mestranda acadêmica em Tecnologia e Gestão Ambiental do Instituto Federal de Educação, Ciência e Tecnologia do Ceará, Campus Fortaleza, Ceará, brendadeassiscarvalho@ gmail.com; ${ }^{3}$ Professora Mestre do curso de engenharia ambiental e sanitária e coordenadora do laboratório Ambiente e Sociedade, do departamento de química e meio ambiente, do Instituto Federal de Educação, Ciência e Tecnologia do Ceará, Campus Maracanaú, Ceará, adrianamr2@ yahoo.com.br

\section{A R T I G O}

Recebido: $25 / 10 / 2019$

Aprovado: 20/03/2020

Palavras-chave:

Biomassa

Eisenia foetida

Reaproveitamento

Key words:

Biomass

Eisenia foetida

Reuse

\section{R E S U M O}

O objetivo deste trabalho foi analisar a viabilidade da vermicompostagem para reaproveitamento dos resíduos orgânicos domésticos (ROD). O trabalho foi realizado por meio da pré-compostagem e vermicompostagem. Na pré-compostagem e vermicompostagem foram testados os tratamentos: T1 (4:1:1 - Folhas + esterco caprino + ROD), T2 (4:1:0,5 - Folhas + esterco caprino + ROD), na proporção de ROD em termos de volume, em que a unidade de medida foi um balde de $15 \mathrm{~L}$. O processo de pré-compostagem foi conduzido ao longo de 30 dias e a temperatura foi monitorada diariamente. No final do processo de pré-compostagem e vermicompostagem o monitoramento foi por meio de análises de umidade, $\mathrm{pH}$, condutividade elétrica, carbono total, nitrogênio total, relação $\mathrm{C} / \mathrm{N}$, fósforo e potássio. Além da caracterização química dos compostos, foram realizadas a contagem das minhocas no início e final da vermicompostagem. Na segunda etapa do processo, a temperatura máxima atingida foi de $39^{\circ}$ e $36^{\circ} \mathrm{C}$ após o $30^{\circ}$ dia, nos tratamentos $\mathrm{T} 1$ e $\mathrm{T} 2$, respectivamente. $\mathrm{Na}$ terceira etapa, o $\mathrm{pH}$ final ficou na faixa de 6,4 a 6,6. $\mathrm{O}$ tratamento $\mathrm{T} 1$ proporcionou melhor adaptação das minhocas. Os valores para relações $\mathrm{C} / \mathrm{N}$ reduziram em todos os tratamentos, indicando a maturação dos compostos. Apesar dos tratamentos não apresentarem todas as condições exigidas para comercialização, nota-se a viabilidade e o potencial da utilização dos resíduos orgânicos biodegradáveis na produção do vermicomposto como uma alternativa prática e sustentável para adubação.

\section{A B S T R A C T}

The objective of this work was to analyze the feasibility of vermicomposting for reuse of domestic organic waste (ROW). The work was carried out through pre-composting and vermicomposting. In the pre-composting and vermicomposting the treatments were tested: T1 (4:1:1 - Sheets + goat manure + DOW), T2 (4:1:0.5 - Sheets + goat manure + DOW), in the proportion of DOW in terms of volume, where the unit of measurement was a $15 \mathrm{~L}$ bucket. The pre-composting process was conducted over 30 days and the temperature was monitored daily. At the end of the pre-composting and vermicomposting process, the monitoring was carried out by means of humidity, $\mathrm{pH}$, electrical conductivity, total carbon, total nitrogen, $\mathrm{C} / \mathrm{N}$ ratio, phosphorus and potassium analyses. In addition to the chemical characterization of the compounds, worm counts were performed at the beginning and end of vermicomposting. In the second stage of the process, the maximum temperature reached was $39^{\circ}$ and $36^{\circ} \mathrm{C}$ after the 30th day, in treatments $\mathrm{T} 1$ and $\mathrm{T} 2$, respectively. In the third stage, the final $\mathrm{pH}$ was in the range of 6.4 to 6.6. The $\mathrm{T} 1$ treatment provided better adaptation of the worms. The values for $\mathrm{C} / \mathrm{N}$ ratios reduced in all treatments, indicating the maturation of the compounds. Although the treatments do not present all the conditions required for commercialization, the work shows the feasibility and potential of using biodegradable organic waste to produce vermicompost as a practical and sustainable alternative for fertilization.

\author{
Revista Verde \\ ISSN 1981-8203 \\ Pombal, Paraíba, Brasil
}

v. 15, n.2, abr.-jun., p.160-167, 2020 doi: $10.18378 /$ rvads.v15i2.7363 


\section{INTRODUÇÃO}

Uma das consequências do estilo de vida da sociedade contemporânea é a elevada produção de resíduos orgânicos biodegradáveis, tornando desafiador seu manejo, tratamento e disposição final, quando poderiam ser aproveitados em diversos fins econômicos e ecologicamente sustentáveis.

Em Maracanaú, Ceará, Brasil, a quantidade estimada de Resíduos Sólidos Urbanos (RSU) representativos foi de 29,10\% recicláveis, 43,90\% compostáveis e 27,00\% rejeitos (SEMA, 2015), mostrando que a maior parcela é de resíduos orgânicos biodegradáveis ou putrescíveis, assim como a média nacional.

Os impactos ambientais associados a estes resíduos decorrem da alta geração em termos quantitativos e da lenta degradabilidade em certos casos, e, em outros, da geração de subprodutos que podem ser tóxicos, cumulativos ou de difícil degradação (BRASIL, 2012), contribuindo para poluição dos recursos hídricos e diminuição do tempo de vida útil dos aterros sanitários.

Uma das alternativas de reciclagem desses resíduos é o uso destes para enriquecimento do solo, ajudando na ciclagem de nutrientes e, consequentemente, na fertilidade natural do solo. De acordo com Lopes e Guilherme (2007) a diminuição da fertilidade do solo afeta, sobretudo, a perda da matéria orgânica (MO) que pode ser considerada como um dos indicadores mais importantes para se medir a qualidade do solo.

Muitos estudos vêm sendo desenvolvidos analisando a viabilidade de se empregar resíduos orgânicos na composição de fertilizantes naturais, visando à dispensa ou diminuição da aplicação de fertilizantes sintéticos (LANDGRAF et al., 2005). Para isso, foram desenvolvidas algumas técnicas para processar resíduos orgânicos biodegradáveis como a compostagem e a vermicompostagem.

A vermicompostagem é o processo de degradação biológica e humificação da matéria orgânica por meio da ação das minhocas e, sobretudo, da flora que vive em seu trato digestivo, microrganismos estes que potencializam a geração de compostos mais ricos em nutrientes assimiláveis pelas plantas (AMORIM, 2002; DORES-SILVA et al., 2011).

Pesquisas têm demonstrado que a vermicompostagem, em comparação ao composto produzido sem as minhocas, acelera a estabilização da matéria orgânica (MO) e produz um composto com menor relação carbono/nitrogênio $(\mathrm{C} / \mathrm{N})$, maior capacidade de troca catiônica (CTC) e maior quantidade de substâncias húmicas (ALBANELL et al., 1988).

A técnica de vermicompostagem pode ser aplicada diretamente na fração orgânica, porém, Amorim (2002) ressalta que a melhor forma desenvolvida é a aplicação da técnica sobre um material já previamente compostado.

Uma grande vantagem desta técnica é a possibilidade de desenvolvimento de sistemas em espaços reduzidos, podendo ser empregada na forma verticalizada, sendo uma inovação com implementação de um método de produção significativamente melhorado.

O objetivo da pesquisa foi analisar a viabilidade da vermicompostagem com minhocas do tipo vermelha-dacalifórnia (Eisenia foetida) para produção de composto a partir do tratamento dos resíduos orgânicos domésticos (ROD).

\section{MATERIAL E MÉTODOS}

O trabalho é um estudo de caso elaborado a partir de pesquisa de campo, bibliográfica e documental e utilizou especificamente o quarteamento dos resíduos, os atributos físicos, físico-químicos e visuais como instrumento de análise.

A pesquisa foi iniciada em setembro de 2016 e concluída em julho de 2017. A área de estudo foi uma residência próxima à Reserva Indígena Santo Antônio dos Pitaguary (RISAP), com as seguintes coordenadas do sistema Universal Transversa de Mercator (UTM) 3.908273, 38.619852, no bairro Horto, distando aproximadamente $34 \mathrm{~km}$ do centro de Fortaleza. A residência apresenta área de $157 \mathrm{~m}^{2}(15,7 \mathrm{~m}$ x $10 \mathrm{~m})$ e o terreno do entorno com área de $206 \mathrm{~m}^{2}$.

A realização da vermicompostagem envolveu a adoção de metodologias propostas por Amorim (2002), com algumas adaptações. Conforme recomendado por Lazcano et al., (2008) foi realizada uma etapa de pré-compostagem (Figura 1).

Figura 1. Sequenciamento das atividades para realização da pesquisa.

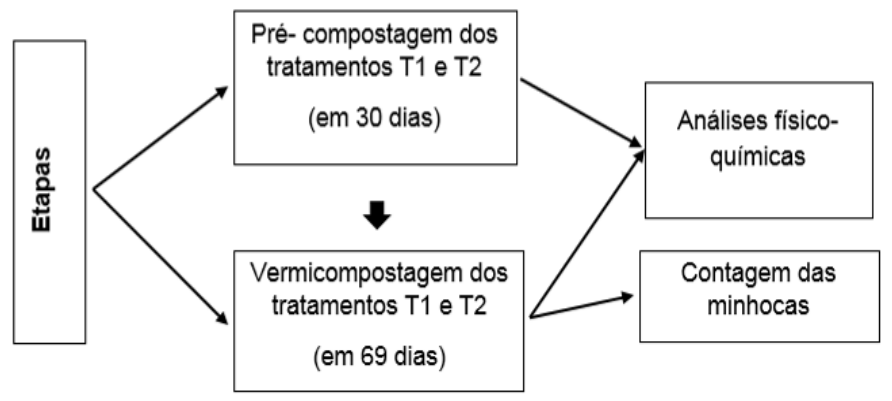

De acordo com Amorim (2002), a vermicompostagem sobre um material já previamente compostado, aumenta a eficiência do processo, assim, os tratamentos passaram por uma pré-compostagem durante um mês. Em sequência foram utilizados os tratamentos T1 e T2 (T1: Folhas, esterco caprino e ROD na proporção de 4:1:1) e T2 (folhas, esterco caprino e ROD na proporção de 4:1:0,5) com os ROD acumulados durante o mês de janeiro de 2017.

\section{Aquisição de materiais e montagem}

Foram utilizados ROD provenientes da própria residência (com exceção de carnes, gordura e alimentos cítricos), folhas e esterco caprino de uma propriedade privada na Reserva Indígena Santo Antônio do Pitaguary (RISAP). A escolha do tipo de esterco se deu em virtude da facilidade e maior disponibilidade do composto.

Durante a pesquisa foram testados dois tratamentos, onde os mesmos se diferiam na proporção de ROD em termos de volume, em que a unidade de medida foi um balde de $15 \mathrm{~L}$. No tratamento T1 utilizou-se a proporção de 4:1:1 e no tratamento T2 a proporção de 4:1:0,5 para os insumos: folhas, esterco caprino e ROD, respectivamente.

Os compostos foram segregados por tratamento, devidamente identificados e isolados, dispostos em forma de leiras. A alocação dos compostos foi realizada através de câmeras 
estáticas abertas, sobre o solo revestido por folhas para evitar a perda de umidade.

As vermicomposteiras foram construídas reutilizando baldes plásticos de $15 \mathrm{~L}$. Os baldes foram fixados verticalmente, de modo a se manterem apoiados um em cima do outro. Entre cada balde foram elaborados furos de cerca $1,0 \mathrm{~cm}$ de diâmetro cada, a fim de permitir a drenagem de líquidos. Nos baldes superiores foram elaborados furos equidistantes logo abaixo das tampas para facilitar a entrada de ar. Os baldes superiores apresentavam tampas, de modo a permitir a entrada dos resíduos orgânicos e a retirada do composto. Os baldes inferiores foram utilizados somente para coleta do percolado. A fim de evitar a fuga das minhocas, bem como a retenção do material, foram colocadas telas entre os baldes. O material foi colocado até atingir $80 \%$ da altura do balde e em seguida o composto foi distribuído uniformemente.

As minhocas utilizadas neste trabalho foram da espécie Eisenia foetida, uma das espécies mais comercializadas no Brasil, popularmente conhecida como a minhoca vermelha-dacalifórnia, ou minhoca de esterco (AQUINO et al., 1992), mesma espécie utilizada por Amorim et al. (2005) e Dores-Silva et al. (2011).

A sobrevivência das minhocas e o bom desenvolvimento da vermicompostagem dependem de um ambiente adequado (Tabela 1).

Tabela 1. Principais parâmetros para o bom desenvolvimento da Eisenia foetida

\begin{tabular}{lccc}
\hline Parâmetros & Nível Ótimo & $\begin{array}{c}\text { Nível } \\
\text { Adequado }\end{array}$ & $\begin{array}{c}\text { Nível } \\
\text { Crítico }\end{array}$ \\
\hline Temperatura $\left({ }^{\circ} \mathrm{C}\right)$ & 25 & $20-30$ & $<5 />37$ \\
Umidade $(\%)$ & $80-85$ & $70-90$ & $<70 />90$ \\
$\mathrm{pH}$ & $5-6$ & $5-9$ & $<5 />8$ \\
$\begin{array}{l}\text { Condutividade } \\
\text { elétrica }\left(\mu \mathrm{S} . \mathrm{cm}^{-1}\right)\end{array}$ & $500-800$ & Até 1200 & $>1200$ \\
\hline Fonte: Gonçalves $(2014)$ adaptado de Edwards (2004) e Lourenço (2010).
\end{tabular}

No experimento as minhocas foram pesadas antes e depois à vermicompostagem, assim como nos trabalhos realizados por Gonçalves (2014) e Loureiro et al. (2007). Foram introduzidas 50 minhocas por vermicomposteira, ou seja, com aproximadamente $35 \mathrm{~g}$ de minhocas.

\section{Condução dos experimentos}

Em ambos os pré-tratamentos os compostos foram umidificados e revolvidos aos 7, 14 e 21 dias após o início do experimento. $\mathrm{O}$ monitoramento diário da temperatura no centro de cada leira no período da manhã às 9h:00min foi realizado com um termômetro de mercúrio. Os demais parâmetros (umidade, $\mathrm{pH}$, condutividade elétrica, carbono total, nitrogênio total, relação $\mathrm{C} / \mathrm{N}$, fósforo e potássio) foram analisados no final do processo de pré-compostagem e vermicompostagem.

Após 30 dias da fase de pré-compostagem todo o material foi transferido para as vermicomposteiras.

As amostras coletadas durante todo o experimento foram analisadas pelo Laboratório de Tecnologia em Processos Ambientais (LTPA) - Campus Maracanaú. As análises feitas para a pré-compostagem e vermicompostagem contemplaram os parâmetros: temperatura, umidade, $\mathrm{pH}$, condutividade elétrica, carbono total, nitrogênio total, relação $\mathrm{C} / \mathrm{N}$, fósforo e potássio.

A análise de umidade seguiu o procedimento descrito pelo Manual de análises químicas de solos, plantas e fertilizantes elaborado pela EMBRAPA (2009). Temperatura foi medida com o auxílio de um termômetro simples de mercúrio. $\mathrm{O} \mathrm{pH}$ foi mensurado por meio de um pHmetro de bancada com eletrodo de vidro. A condutividade elétrica foi obtida com o auxílio de um condutivímetro do modelo FTP 903. O Carbono total foi determinado por oxidação da matéria orgânica em solução ácida e titulada com dicromato com sulfato ferroso amoniacal. Para determinação de nitrogênio total foi utilizada a digestão sulfúrica e a destilação das amostras. A determinação do fósforo e do potássio foi realizada espectrofotometricamente.

Além das análises, mostrando a caracterização química dos compostos, foi feita a contagem e pesagem das minhocas antes e depois do processo de vermicompostagem.

A análise dos dados foi realizada de forma visual e comparativa de acordo com os atributos químicos obtidos pelas análises dos compostos antes e após o processo de vermicompostagem.

\section{RESULTADOS E DISCUSSÃO}

De acordo com a Figura 2, durante a pré-compostagem, os dois tratamentos não chegaram à fase termofílica, com temperaturas próximas ou maiores aos $50^{\circ} \mathrm{C}$. $\mathrm{O}$ tratamento $\mathrm{T} 1$, no segundo dia, atingiu a máxima de $39^{\circ} \mathrm{C}$. Durante os sete primeiros dias a temperatura média em ambos os tratamentos se manteve superior a $30^{\circ} \mathrm{C}$, indicando uma elevação da atividade microbiana.

Figura 2. Evolução da temperatura durante a pré-compostagem nos tratamentos T1 (Folhas, esterco caprino e ROD na proporção de 4:1:1) e T2 (folhas, esterco caprino e ROD na proporção de $4: 1: 0,5)$. As setas indicam as épocas em que os compostos foram revirados.

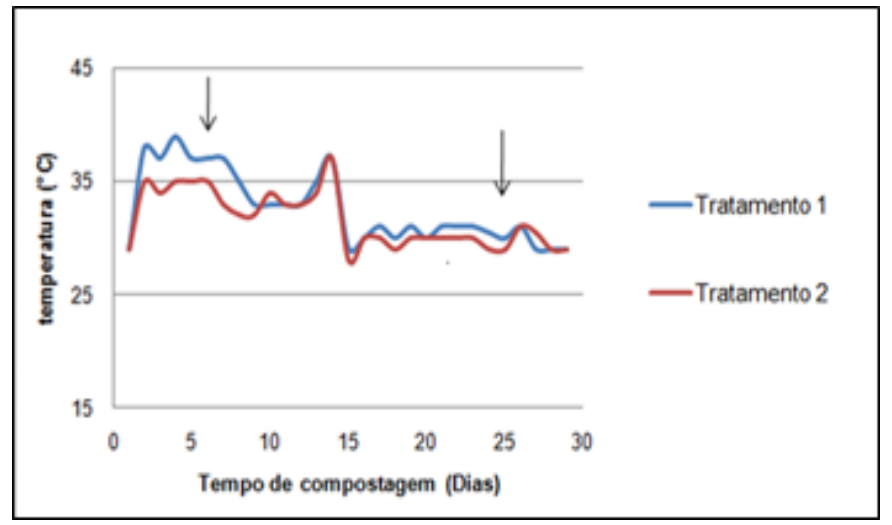

A duração das fases da compostagem, especialmente a termofílica, depende da natureza da matéria orgânica a ser compostada e da eficiência do processo, a qual é, dentre outros fatores, determinada pelo grau de arejamento (TUOMELA et al., 2000). Constatou-se que quando realizada aeração dos compostos, o material sofria elevação de temperatura. Isso é explicado por Inácio e Miller (2009) quando os autores afirmam 
que um ambiente aeróbico propicia uma decomposição mais rápida da matéria orgânica e consequente acréscimo na temperatura pela plena atividade dos microrganismos. Adicionalmente, acredita-se que os resultados supracitados foram determinados pelo pequeno tamanho da leira, dificultando a elevação da temperatura.

Durante os experimentos foi observada uma brusca diminuição da temperatura em ambos os tratamentos entre os dias 13 e 15 de fevereiro. Esse fenômeno pode ser atribuído a uma possível relação entre a variação de temperatura e umidade local devido às chuvas que ocorreram entre os dias 11 e 19 de fevereiro de 2017, e por isso as medições foram realizadas ao final da tarde.

Os tratamentos $\mathrm{T} 1$ e $\mathrm{T} 2$ apresentaram perfis de temperatura diferentes. Ambos atingiram temperaturas elevadas já no segundo dia de processo, mas o tratamento $\mathrm{T} 1$ alcançou em média $5{ }^{\circ} \mathrm{C}$ a mais que o tratamento $\mathrm{T} 2$. Os intervalos de temperatura evidenciados nos 30 dias do processo de précompostagem apontaram que a temperatura de $\mathrm{T} 1$ variou entre os 28 a $39{ }^{\circ} \mathrm{C}$, enquanto o T2 variou de 28 a $36{ }^{\circ} \mathrm{C}$. Esta menor variação do $\mathrm{T} 2$ em relação ao $\mathrm{T} 1$ se deu possivelmente pelo fato do T2 apresentar uma proporção menor de ROD. Após o $17^{\circ}$ dia houve a estabilização e aproximação da temperatura de ambos os tratamentos à temperatura ambiente. De modo geral, o tratamento T1 apresentou maior média geral de temperatura ao longo do processo de pré-compostagem.

Observa-se na Tabela 2 que o teor de umidade em ambos os tratamentos apresentou valores próximos a 50\%, o que está dentro do limite sugerido pela literatura, cujo valor deve estar entre 40-70\% (KIEHL, 2004). Para valores acima disso, segundo Barreira (2005), "os poros no interior da matriz sólida começam a ser preenchidos com água livre, impedindo a difusão de oxigênio o que permite que condições anaeróbias se desenvolvam".

A variação final de temperatura, em ambos os tratamentos, também apresentou valores aceitáveis pela literatura. Para valores abaixo de $15^{\circ} \mathrm{C}$ e acima de $40^{\circ} \mathrm{C}$ as minhocas morrem rapidamente, devido à baixa de seu metabolismo (LOURENÇO, 2010).

Tabela 2. Caracterização final dos compostos na pré-compostagem nos tratamentos T1 (Folhas, esterco caprino e ROD na proporção de 4:1:1) e T2 (folhas, esterco caprino e ROD na proporção de 4:1:0,5).

\begin{tabular}{lccccccccc}
\hline \multicolumn{1}{c}{ Tratamentos } & $\begin{array}{c}\text { Umidade } \\
(\%)\end{array}$ & $\begin{array}{c}\text { Temp. } \\
\left({ }^{\circ} \mathrm{C}\right)\end{array}$ & $\mathrm{pH}$ & $\begin{array}{c}\text { C.E. } \\
\left(\mu \text { S.cm }{ }^{-1}\right)\end{array}$ & $\begin{array}{c}\text { C org. } \\
(\%)\end{array}$ & $\begin{array}{c}\text { N Total } \\
(\%)\end{array}$ & $\mathrm{C} / \mathrm{N}$ & $\mathrm{P}(\mathrm{mg} / \mathrm{L})$ & $\begin{array}{c}\mathrm{K} \\
(\mathrm{mg} / \mathrm{L})\end{array}$ \\
\hline $\mathrm{T} 1$ & 49,95 & 28,0 & 7,2 & 86,00 & 7,76 & 0,42 & $19 / 1$ & 12,16 & 21,2 \\
$\mathrm{~T} 2$ & 50,18 & 28,0 & 7,2 & 64,92 & 11,82 & 0,51 & $23 / 1$ & 64,68 & 4,1 \\
\hline
\end{tabular}

Quanto ao $\mathrm{pH}$, todos os valores estavam dentro do limite proposto por Kiehl (1985), que varia inicialmente na faixa de 4,5 a 9,5 .

Para a condutividade elétrica foram observados valores baixos, considerando a faixa de 500 a $1200 \mu{\mathrm{S} . \mathrm{cm}^{-1}}^{-1}$, ideal para o bom desenvolvimento das minhocas. Entre os dias 11 e 19 de fevereiro de 2017, fortes chuvas influenciaram a estrutura onde estava alocado o experimento, portanto, acredita-se que a baixa concentração de sais nos tratamentos pode estar relacionada ao carreamento por escoamento superficial em virtude das águas pluviais.

A partir das análises é possível perceber que ambos os tratamentos apresentaram relações $\mathrm{C} / \mathrm{N}$ um pouco abaixo da relação de 30/1, valor considerado adequado por Kiehl (1985). A maior diferença foi constatada para o tratamento $\mathrm{T} 1$, e o fato pode ser explicado pelo baixo percentual de $\mathrm{N}$ (menor que 1\%) e baixo teor de carbono, o que propiciou a diminuição na relação $\mathrm{C} / \mathrm{N}$.

De acordo com Kiehl (1985) durante a pré-compostagem ocorre redução de carbono orgânico devido à degradação da matéria orgânica, e o aumento do nitrogênio total, em virtude da mineralização. Os trabalhos de Amorim (2002) e Bernardi (2011) também apresentaram tal comportamento. $\mathrm{O}$ tratamento $\mathrm{T} 1$ apresentou-se, ao final dos 30 dias de pré-compostagem, com relação $\mathrm{C} / \mathrm{N}$ de aproximadamente 19/1, valor próximo ao determinado pela Instrução Normativa $\mathrm{n}^{\circ} .25$ de 23 de julho de 2009 (BRASIL, 2009) para compostos já maturados.
Após os 30 dias de pré-compostagem, os tratamentos T1 e T2 já estavam bem descaracterizados (Figura 3). A degradação dos ROD foi bastante visível. Ambos os tratamentos sofreram alterações visuais. Foi observado bom aspecto granulométrico, textura do esterco e no composto em sua totalidade. Após a précompostagem o odor e a sensação ao tato estavam agradáveis.

A variação de temperatura nos dois tratamentos após a vermicompostagem foi semelhante, ficou em torno de $28^{\circ} \mathrm{C}$. O microclima da vermicomposteira, em especial o fator temperatura, afeta diretamente as minhocas, influenciando seus processos e taxas metabólicas (EDWARDS, 2004). De modo geral, a temperatura média nos dois tratamentos foi equivalente à $27^{\circ} \mathrm{C}$. Conforme Edwards (2004) e Lourenço (2010) estes valores foram considerados adequados (entre 20 e $30^{\circ} \mathrm{C}$ ).

Ao término do período de vermicompostagem, os tratamentos $\mathrm{T} 1$ e $\mathrm{T} 2$ se apresentavam totalmente descaracterizados (Figura 4), restando-lhes do material de origem apenas os pedaços maiores de folhas, mas já em estágio avançado de degradação. Uma significativa diferença visual foi observada quanto aos aspectos dos materiais, bem como a aparência granulométrica, no início e no final da vermicompostagem. $\mathrm{O}$ vermicomposto em ambos os tratamentos apresentaram coloração mais escura, uniforme e sem odor. Esses aspectos ocorrem devido à atividade de microrganismos do esterco e ação das minhocas. 
Figura 3. Aspectos dos materiais da pré-compostagem nos tratamentos T1 (Folhas, esterco caprino e ROD na proporção de 4:1:1) A) antes e B) depois; Aspectos dos materiais da pré-compostagem nos tratamentos T2 (folhas, esterco caprino e ROD na proporção de 4:1:0,5) C) antes e D) depois.
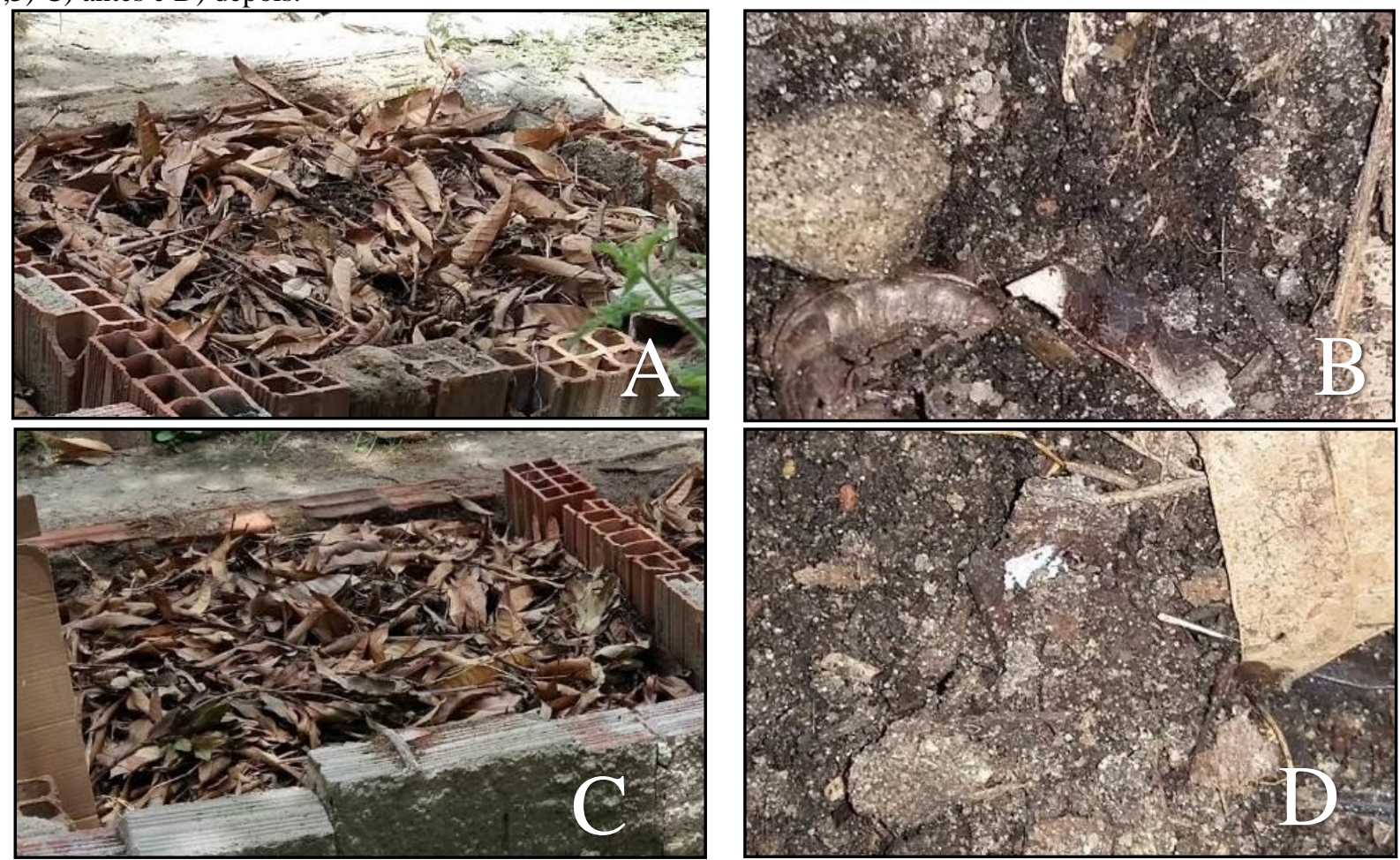

Figura 4. Aspectos dos materiais da vermicompostagem nos tratamentos T1 (Folhas, esterco caprino e ROD na proporção de 4:1:1) A) antes e B) depois; Aspectos dos materiais da vermicompostagem nos tratamentos T2 (folhas, esterco caprino e ROD na proporção de 4:1:0,5) C) antes e D) depois.
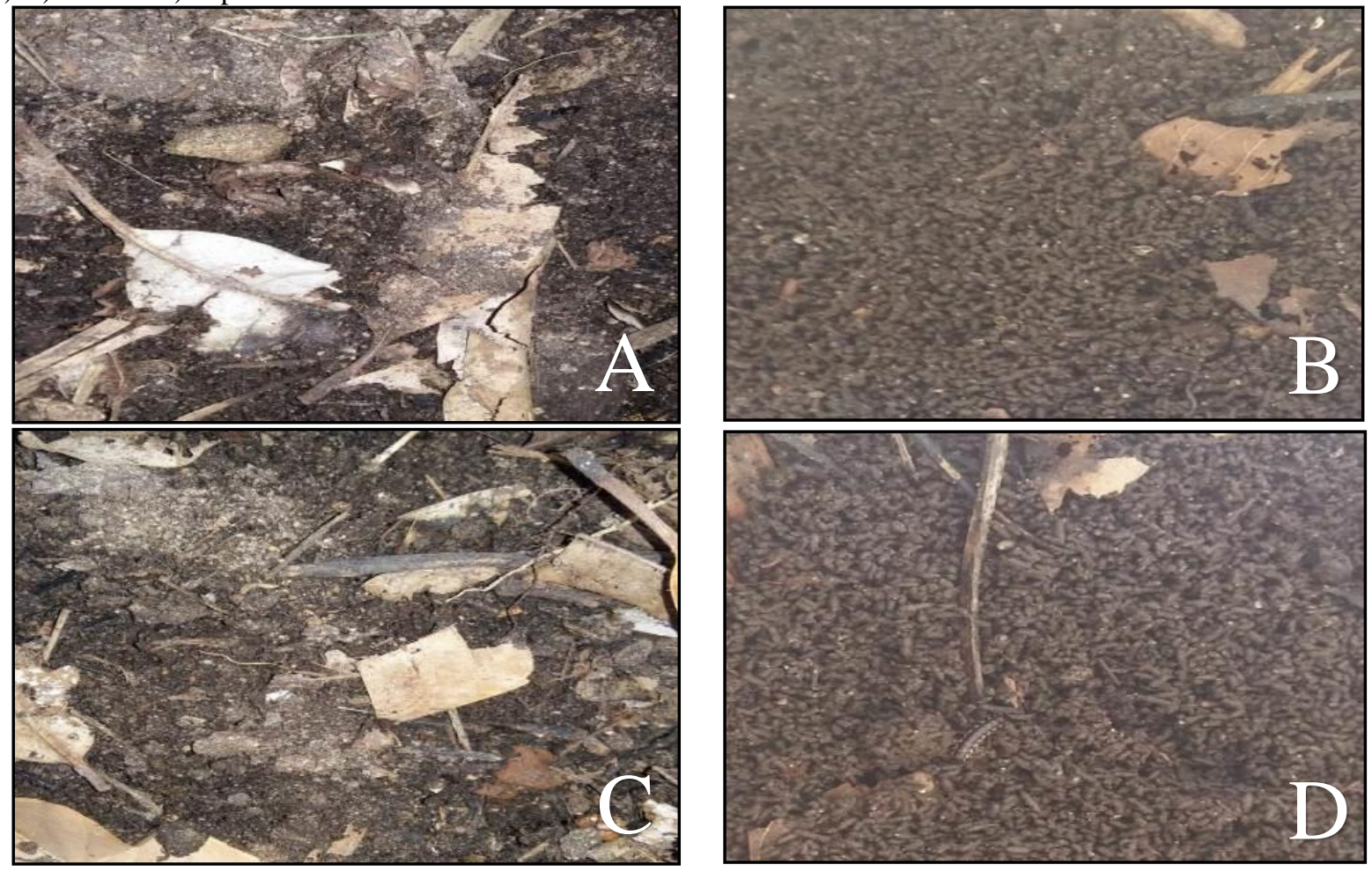
A vermicompostagem fornece material estabilizado, especialmente quanto ao $\mathrm{pH}$, em tempo menor, se comparado com a compostagem (CASTILHOS et al., 2008). As análises revelaram a diminuição do $\mathrm{pH}$ em ambos os tratamentos. Albanell et al. (1988) atribuem a diminuição do pH à produção de $\mathrm{CO}_{2}$ e ácidos orgânicos pela atividade microbial durante o processo de vermicompostagem. Os tratamentos T1 e T2 apresentaram valores próximos à neutralidade. A proximidade de valores entre os tratamentos pode ocorrer em virtude de os mesmos possuírem os mesmos compostos e proporções similares (Tabela 5).

Tabela 5. Caracterização final dos compostos na vermicompostagem nos tratamentos T1 (Folhas, esterco caprino e ROD na proporção de 4:1:1) e T2 (folhas, esterco caprino e ROD na proporção de 4:1:0,5).

\begin{tabular}{lccccccccc}
\hline \multicolumn{1}{c}{ Tratamentos } & $\begin{array}{c}\text { Umidade } \\
(\%)\end{array}$ & $\begin{array}{c}\text { Temp. } \\
\left({ }^{\circ} \mathrm{C}\right)\end{array}$ & $\mathrm{pH}$ & $\begin{array}{c}\text { C.E. } \\
\left(\mu \text { S.cm }{ }^{-1}\right)\end{array}$ & $\begin{array}{c}\text { C org. } \\
(\%)\end{array}$ & $\begin{array}{c}\text { N Total } \\
(\%)\end{array}$ & $\mathrm{C} / \mathrm{N}$ & $\mathrm{P}(\mathrm{mg} / \mathrm{L})$ & $\begin{array}{c}\mathrm{K} \\
(\mathrm{mg} / \mathrm{L})\end{array}$ \\
\hline T1 & 65,0 & 27,1 & 6,6 & 419,5 & 23,4 & 1,3 & $18 / 1$ & 76,85 & 27,11 \\
$\mathrm{~T} 2$ & 51,0 & 26,9 & 6,4 & 403,7 & 20,0 & 1,1 & $18 / 1$ & 100,13 & 47,53 \\
\hline
\end{tabular}

Segundo Carlesso et al. (2011) as minhocas têm preferência por matéria orgânica pouco ácida. Há indicações de que as minhocas toleram valores para $\mathrm{pH}$ entre 5 e 8 , com prejuízo às suas atividades apenas quando estão fora desta faixa (LOURENÇO, 2010). Estas indicações caracterizam ambos os tratamentos em condições aceitáveis para o desenvolvimento das minhocas quanto ao parâmetro $\mathrm{pH}$. Segundo a Instrução Normativa $n^{\circ} .25$, de 23 de julho de 2009 (BRASIL, 2009) - o valor de $\mathrm{pH}$ mínimo aceitável para a comercialização de vermicomposto no Brasil é igual a 6,0. Deste modo, para o parâmetro $\mathrm{pH}$, todos os tratamentos, deste estudo, atendem tal legislação.

A condutividade elétrica dos dois tratamentos apresentou valores próximos. Segundo Edwards (2004) e Lourenço (2010) o nível adequado para a sobrevivência de minhocas em um resíduo está situado entre 500 e $1200 \mu \mathrm{S} . \mathrm{cm}^{-1}$, embora os valores obtidos nos tratamentos testados não estejam compreendidos dentro do intervalo, os valores estão próximos à ordem de grandeza estimada. $\mathrm{O}$ aumento de sais solúveis quando comparado à précompostagem deve-se, provavelmente, à mineralização da matéria orgânica pelas minhocas e pelos micro-organismos presentes em seu intestino.

Pode-se observar que, após a vermicompostagem, os valores de umidade para T1 e T2 se diferenciaram. No tratamento $\mathrm{T} 1$ ocorreu um aumento de $21,54 \%$ em relação ao tratamento $\mathrm{T} 2$. Segundo a Instrução Normativa no 25, de 23 de julho de 2009 (BRASIL, 2009) - o valor máximo do teor de umidade aceitável para a comercialização de vermicomposto no Brasil é de $50 \%$. Deste modo, os tratamentos não atendem à legislação. No entanto, T2 alcançou valores muitos próximos ao valor aceitável.

A variação do nitrogênio total ocorreu conforme esperado, com aumento da concentração. Durante o processo de mineralização e respiração, tanto dos microrganismos quanto das minhocas, a matéria orgânica evolui, havendo, desta maneira, uma concentração dos nutrientes. Durante o processo de vermicompostagem as minhocas fixam parte do carbono em sua biomassa e outra parte é transformada em $\mathrm{CO}_{2}$ e perdida para o meio externo, ocorrendo, assim, a mineralização do carbono (DORES-SILVA et al., 2011). Outros dois pontos importantes são os acréscimos em razão dos excrementos das minhocas, ricos em nitrogênio, e oriundos do próprio corpo destes anelídeos, que liberam expressiva quantidade deste nutriente quando morrem (BATTIROLA et al., 1998).

Analisando sob a ótica de aplicação do vermicomposto ao solo, a Instrução Normativa $n^{\circ}$. 25/2009 prevê que a porcentagem mínima de carbono orgânico deve ser de $10 \%$, enquanto que para o nitrogênio total é de $0,5 \%$ (BRASIL, 2009). De acordo com as análises laboratoriais, os teores finais de carbono orgânico foram de 23,4\% e 20,0\%, respectivamente para T1 e T2. Deste modo, tanto para o carbono quanto para o nitrogênio os valores obtidos nos vermicompostos deste estudo satisfazem as condições da legislação. Todos os tratamentos apresentaram redução da relação C/N comparado ao processo de pré-compostagem, o que está em consonância com o que é previsto por Kiehl (1985).

Para Dores-Silva et al. (2011), a relação $\mathrm{C} / \mathrm{N}$ é um dos indicativos da maturidade e grau de estabilização de um composto. A aceleração no processo de humificação promovido pelas minhocas resulta na diminuição significativa na razão $\mathrm{C} / \mathrm{N}$. A Instrução Normativa no. 25/2009 propõe que o valor máximo para a relação, aceitável para a comercialização de vermicomposto no País, seja igual a 14 (BRASIL, 2009). Sendo assim, nenhum dos tratamentos estaria apto a ser comercializado após os 69 dias de estudo. A alternativa cabível seria prolongar o tempo de vermicompostagem, visto que os tratamentos seguem em tendência de diminuição de valores de relação $\mathrm{C} / \mathrm{N}$ ao longo do tempo.

De acordo com Atiyeh et al. (2001), a acelerada humificação do vermicomposto produz decréscimo da $\mathrm{C} / \mathrm{N}$ e aumento de nutrientes minerais $(\mathrm{P}, \mathrm{K}$ e N$)$ e está relacionada com a mineralização da $\mathrm{MO}$ pelas minhocas. Conforme análise apresentada na tabela 5, em todos os tratamentos testados, após o processo de vermicompostagem obtiveram aumento significativo nos níveis de fósforo e potássio, se comparados aos valores do processo de pré-compostagem. O aumento desses parâmetros pode estar associado à capacidade das minhocas, por meio de seu metabolismo, de quebrar as estruturas de compostos orgânicos (SILVA et al., 2002). Após a inoculação de minhocas Eisenia foetida, a ampliação desse elemento foi superior, devido à mineralização do fósforo orgânico.

Apesar da vermicompostagem levar à mortalidade das minhocas adultas, como resultado da falta de alimento decorrente da produção do húmus, observada por Aquino et al. (1994), neste trabalho, foram mantidas a população inicial das minhocas 
adultas em ambos os tratamentos, com acréscimo de $4 \%$ e $2 \%$ da quantidade de minhocas adultas nos tratamentos T1 e T2, respectivamente.

A espécie utilizada nos experimentos apresentou maior ganho de massa no tratamento T1, melhor adaptação ao alimento fornecido, bem como não foi observada a fuga em massa das matrizes. Lavelle et al. (2004) afirmam que a maior diferença entre experimentos em escala pequena e o mundo real é que em experimentos confinados, minhocas têm oportunidades limitadas para encontrar comida e mover-se. Isto provavelmente mostra porque quase sempre elas perdem peso ou morrem em experimentos de laboratório, um comportamento que não foi observado durante a pesquisa, pois no tratamento $\mathrm{T} 1$ foi mantida a biomassa das espécies e aumento de 22,6 \% dessa biomassa no tratamento T2. A adaptação das minhocas foi perceptível em ambos tratamentos, contudo o tratamento $\mathrm{T} 1$ proporcionou maior incremento da biomassa de minhocas.

\section{CONCLUSÕES}

O uso de quantidades diferentes de resíduos orgânicos domésticos (ROD) biodegradáveis resultam em compostos maturados e vermicompostados com características químicas diferentes. Maiores teores de N, P e K e redução da relação C/N foram observados nos materiais produzidos com a précompostagem. Os produtos obtidos com a vermicompostagem, após 30 dias de pré-compostagem, foram similares, exceto para os teores de umidade, em que o tratamento com maior quantidade de ROD apresentou aumento de $27,4 \%$ em relação ao tratamento com menor quantidade. Os vermicompostos produzidos podem ser utilizados como uma alternativa prática e sustentável para adubação em substituição aos fertilizantes minerais e as quantidades a serem aplicadas devem ser ajustadas em função de sua composição específica.

\section{REFERÊNCIAS}

ALBANELL, E.; PlAIXATS, J.; CABRERO, T. Chemical changes during vermicomposting (Eisenia fetida) of sheep manure mixed with cotton industrial wastes. Biology and Fertility of Soils, v. 6, p. 266-269. 1988. 10.1007/BF00260823

AMORIM, A. C. Caracterização dos dejetos de caprinos: reciclagem energética e de nutrientes. Dissertação (Mestrado em Produção Animal) - Universidade Estadual Paulista, Faculdade de Ciências Agrárias e Veterinárias. Jaboticabal, 2002.

AMORIM, A.C.; LUCAS JÚNIOR, J. de; RESENDE, K. T. de. Compostagem e vermicompostagem de dejetos de caprinos: efeito das estações do ano. Engenharia Agrícola, v.25, n.1, p.5766, 2005. 10.1590/S0100-69162005000100007

AQUINO, A. M. de; ALMEIDA, D. L de; SILVA, V. F. da. Utilização de minhocas na estabilização de resíduos orgânicos: vermicompostagem. Comunicado técnico - Embrapa Agrobiologia. n. 8, p.1-6. 1992.

ATIYEH, R. M.; EDWARDS, C. A.; SUBLER, S.; METZGER, J. D. Pig manure vermiccompost as a component of a horticultural bedding plant medium: effects on physicochemical proprieties and plant growth. Bioresource Technology, v. 78, p. 11-20. 2001. 10.1016/S0960-8524(00)00172-3

BATTIROLA, D. M.; TORRES, V. S.; SCHERER, E. E. Avaliação da compostagem do lixo orgânico e do esterco bovino por diferentes agentes biológicos. Biotemas, v.11, n. 2. p. 71-84. 1998. $10.5007 / \% 25 \mathrm{x}$

BERNARDI, F. H. Uso do processo de compostagem no aproveitamento de resíduos de incubatório e outros de origem agroindustrial. Dissertação (Mestrado em Engenharia Agrícola) - Centro de Ciências Exatas e Tecnologias, Universidade Estadual do Oeste do Paraná, Cascavel, 2011.

BRASIL. Instituto de Pesquisa Econômica Aplicada. Diagnóstico dos Resíduos Orgânicos do Setor Agrossilvopastoril e Agroindústrias Associadas. Brasília: IPEA, 2012.

BRASIL. Ministério da Agricultura, Pecuária e Abastecimento. Instrução Normativa no 25, de 23 de julho de 2009. Disponível em:

<http://extranet.agricultura.gov.br/sislegisconsulta/consultarLeg islacao.do?operacao=visualizar\&id=20542 > . Acesso em: 13 jul. 2017.

CARLESSO, W. M.; RIBEIRO, R.; HOEHNE, L. Tratamento de resíduos a partir de compostagem e vermicompostagem. Revista Destaques Acadêmicos, [S.1.], v. 3, n. 4, 2012.

CASTILHOS, R. M. V.; DICK, D. P.; CASTILHOS, D. D.; MORSELLI, T. B. A. G.; COSTA, P. F. P. da.; CASAGRANDE, W. B.; ROSA, C. M. da. Distribuição e caracterização de substâncias húmicas em vermicompostos de origem animal e vegetal. Revista Brasileira Ciência Solo, v.32, p. 2669-2675, 2008. 10.1590/S0100-06832008000700009

DORES-SILVA, P. R.; LANDGRAF, M. D.; REZENDE, M. O. O. Acompanhamento químico da vermicompostagem de lodo de esgoto doméstico. Química Nova, v. 34, n. 6, p. 956-961, 2011. 10.1590/S0100-40422011000600008

EDWARDS, C. A. Earthworm ecology. Rev. ed. of: Earthworm ecology / edited by Clive A. Edwards 2nd ed. 417 p. 2004.

EMBRAPA, Manual de análises químicas de solos, plantas e fertilizantes / editor técnico, Fábio Cesar da Silva. - 2. ed. Revisão ampliada. - Brasília, DF: Embrapa Informação Tecnológica, 2009.

GONÇALVES, F. Tratamento de camas de equinos por compostagem e vermicompostagem. 2014. 133 f. TCC (Graduação) - Curso de Engenharia Ambiental, Universidade Tecnológica Federal do Paraná, Londrina, 2014.

KIEHL. E. J. Manual da compostagem: maturação e qualidade do composto. 4. ed. Piracicaba: E. J. KIEHL. p. 173, 2004. 
KIEHL. Fertilizantes orgânicos. Piracicaba: Ceres, p. 492, 1985.

INÁCIO, C. T.; MILLER, P. R. M. Compostagem: ciência e prática para gestão de resíduos orgânicos. Rio de Janeiro: EMBRAPA Solos, p. 156, 2009.

LANDGRAF, M. D.; MESSIAS, R. A.; REZENDE, M. O. O. A importância ambiental da vermicompostagem: vantagens e aplicações. São Carlos: Rima, p. 106, 2005.

LAVELLE, P.; CHARPENTIER, F.; VILLENAVE, C.; ROSSI, JEAN-PIERRE; DEROUARD, L.; PASHANASI, B.; ANDRÉ, J.; PONGE, JEAN-FRANÇOIS; BERNIER, N. Effects of earthworms on soil organic matter and nutrient dynamics at a landscape scale over decades. In: EDWARDS, C. A. Earthworm Ecology. 2. ed. Florida: CRC PRESS, p. 145- 160, 2004.

LAZCANO, C.; GÓMEZ-BRANDÓN, M.; DOMÍNGUEZ, J. Comparison of the effectiveness of composting and vermicomposting for the biological stabilization of cattle manure. Chemosphere, v. 72, n. 7, p.1013-1019, 2008. $\underline{10.1016 / \text { j.chemosphere.2008.04.016 }}$

LOPES, A. S.; GUILHERME, L. R. G. Fertilidade do solo e produtividade agrícola. Lavras: Universidade Federal de Lavras, p. 1-63, 2007.

LOUREIRO, D. C.; AQUINO, A. M. de; ZONTA, E.; LIMA, E. Compostagem e vermicompostagem de resíduos domiciliares com esterco bovino para a produção de insumo orgânico. Pesquisa Agropecuária Brasileira, Brasília, v. 42, n. 7, p.1043-1048, 2007. 10.1590/S0100-204X2007000700018

LOURENÇO, N. M. G. Características da minhoca Epígea Eisenia Foetida - benefícios, características e mais-valias ambientais decorrentes da sua utilização. 2010. Disponível em $<$ http://www.slideshare.net/FuturambGSR/caractersticas-daminhoca-epgea-eisenia-foetida-benefcios-caractersticas-eemaisvalias-ambientais-decorrentes-da-sua-utilizao>. Acesso em 10. Jun. 2017.

SEMA, Secretaria do Meio Ambiente do Ceará. Plano estadual de resíduos sólidos - PERS: estudos de prospecção e escolha de cenários de referência. 2015. Disponível em: <http://www.sema.ce.gov.br/attachments/article/44259/CENAR IOS-min.pdf $>$. Acesso em: 16 fev. 2017.

SILVA, C. D. da; COSTA, L. M. da; MATOS, A. T. de; CECON, P. R.; SILVA, D. D. Vermicompostagem de lodo de esgoto urbano e bagaço de cana-de-açúcar. Revista Brasileira de Engenharia Agrícola e Ambiental, v. 6, p. 487-491, 2002. 10.1590/S1415-43662002000300018

TUOMELA, M.; VIKMAN, M.; HATAKKA, A.; ITÄVAARA, M. Biodegradation of lignin in a compost environment: a review. Bioresource Technology. v. 72, n. 2, p. 169-183, 2000. 10.1016/S0960-8524(99)00104-2 